\title{
ÖZEL SAYI EDİTÖRÜNÜN NOTU: “70. YILINDA BRETTON WOODS ANLAŞMASI” ÜZERINE
}

\author{
Hakan MIHÇI \\ Prof. Dr., Hacettepe Üniversitesi, İktisat Bölümü \\ hakan@hacettepe.edu.tr
}

$\mathrm{Bu}$ notta Hacettepe Üniversitesi İktisadi ve İdari Bilimler Fakültesi Dergisi'nin 2016 y1lı Özel Sayısına temel oluşturan "70. Yllinda Bretton Woods Anlaşması Sempozyumu" hakkında bilgi aktarmak ve sayının ortaya çıkış hikayesini sizlerle paylaşmak istiyorum.

Sempozyumun fikir babasının Prof. Dr. Bilsay Kuruç Hocamız olduğunu belirterek başlamak istiyorum. Bilsay Hoca, Türk Sosyal Bilimler Derneği (TSBD)'nin 26 Nisan 2014 tarihinde yapılan Genel Kurulu'nda içinde bulunduğumuz yılın Bretton Woods Anlaşmasının 70. Yılına karşılık geldiğini vurguladıktan sonra, bu önemli yıldönümünü akademik bir etkinlik düzenleyerek irdelemenin anlamlı olacağını belirtmişti. Bu önerinin Genel Kurulda seçilen TSBD'nin yeni Yönetim Kurulu tarafından da benimsenerek 2014 yılı bitmeden hayata geçirilmesi hedeflendi. Etkinliğin Ankara'da bulunan bir devlet üniversitesinde gerçekleştirilmesi düşünüldü. $\mathrm{Bu}$ çerçevede daha önce benzer etkinliklerde işbirliği yapılan üniversitelerden biri olan Hacettepe Üniversitesi İktisat Bölümü’ne yönelindi.

Hacettepe Üniversitesi İktisat Bölümü 2-3 Aralık 2010 tarihlerinde "Küresel Kriz ve İsssizlik" başlıklı Sempozyumu TSBD ve Uluslararası Çalışma Örgütü (ILO) Türkiye Temsilciliği'nin ortak organizasyonu kapsamında başarıyla gerçekleştirmişti. Dolayısıyla, İktisat Bölümü ile TSBD’nin işbirliği deneyiminin geçmişi bulunmaktaydı. Tasarlanan yeni bilimsel etkinlikle bu işbirliği deneyiminin ileri boyuta taşınması gündeme gelmekteydi. Sonuç olarak, 5 Aralık 2014 tarihinde gün boyuna yayılan akademik etkinlik Hacettepe Üniversitesi İktisat Bölümü ile TSBD’nin ortak işbirliğinde düzenlenen ilgi çekici bir etkinlik olarak kayıtlara geçti. Beytepe Yerleşkesi, İktisadi ve İdari Bilimler Fakültesi, Tuğrul Çubukçu Salonu İktisat Bölümünün diğer tüm etkinliklerinde olduğu gibi bu etkinliğin de mekânını oluş̧urdu. Sempozyum o kadar büyük bir ilgiyle karşılandı ki, 230 oturma kapasitesine sahip salon ayakta duranlar, getirilen ek sandalyelere oturanlar, oturumdan oturuma dolup boşalanlarla birlikte yaklaşık 400 kişiye ev sahipliği yapmaya çalıştı. Sempozyuma sadece 
Ankara'nın tüm üniversitelerinden öğrenci ve akademikler değil, Ankara dışından kimi üniversitelerinden araştırmacılar da yoğun bir ilgi gösterdi.

Sempozyuma farklı kurumlardan (Ankara Üniversitesi, Siyasal Bilgiler Fakültesi, Atılım Üniversitesi, Bilkent Üniversitesi, Hacettepe Üniversitesi, İş Yatırım, Orta Doğu Teknik Üniversitesi) konunun uzmanı çok değerli araştırmacılar davet edilmişti. Katılımcılarımız, kalabalık ve hararetli ortama rağmen, sundukları bildirilerle dinleyicilerin ilgisini sürekli diri tutmayı becerecek yetkinlikteydiler. Sempozyumda yaptıkları sunuşlarla katkı sunan bilim insanları ve araştırmacılar şunlardı: Korkut Boratav, Naci Canpolat, Hasan Cömert, Muammer Kaymak, Ahmet Haşim Köse, Bilsay Kuruç, Şant Manukyan, Hüseyin Özel, Gökçer Özgür, Sinan Sönmez, Galip Yalman ve Erinç Yeldan.

Sempozyum Bilsay Kuruç’un "Çerçeve Sunuş"unu izleyen üç oturum altında düzenlenmişti. Hakan Mıhı'nın oturum başkanlığında öğleden önce gerçekleştirilen birinci oturumun başlı̆̆ "Bretton Woods Sisteminin Kökenleri ve Yapısal Dayanakları”ydı. Öğleden sonra iki oturum tasarlanmıştı. İlki Fikret Şenses’in oturum başkanlığında gerçekleştirilen "Bretton Woods Sistemi ve Kapitalizmin Ekonomi Politiği" başlıklı oturum, sonuncusu da Pınar Bedirhanoğlu'nun başkanlığında yapılan "Bretton Woods Anlaşması ve Uluslararası Para Sistemi" başlıklı oturumdu. Tüm bu oturumlarda 11 farklı sunum yer ald.

Sempozyum programının oluşturulması aşamasında pek çok hocamızdan destek alındı. Bunların başında Bilsay Kuruç Hoca'yı anmak gerekiyor. Bilsay Hoca Sempozyum programının oluşturulmasında değerli katkılar sundu. Bu çerçevede TSBD Başkanı Galip Yalman ve Ahmet Haşim Köse Hocalarımızın katkılarını da anmadan geçmek olmaz. Kendilerine müteşekkiriz.

Sempozyumun gerçekleştirilmesinde çok ciddi katkılar alındı. Bu katkıların bir kısmı kurumsal, bir kısmı da bireyseldi. Sempozyumun ortak organizatörlerinden biri yukarıda da belirtildiği gibi TSBD’ydi. TSBD hem kurumsal olarak, hem de Yönetim Kurulu üyeleri aracılığıyla katkılarını esirgemedi. Hacettepe Üniversitesi de kurumsal düzeyde önemli destek sundu. Sempozyum Hacettepe Üniversitesi Bilimsel Araştırmalar Birimi (BAB) tarafından maddi olarak desteklendi. Hacettepe Üniversitesi İktisadi ve İdari Bilimler Fakültesi Dekanlığ Sempozyuma yakından destek verdi. Sempozyum mekânını kullanımımıza açtılar. Sempozyum afişlerinin basılmasını sağladılar. İktisat Bölümündeki çalışma arkadaşlarımız Sempozyumun her aşamasında destekçiydiler. Bazı meslektaşlarımızın katkılarının altını özellikle çizmek isterim. Doç. 
Dr. Muammer Kaymak, Doç. Dr. Gökçer Özgür, doktora adayları asistan arkadaşlarımız Pınar Sezer Sorkun, Selin Zengin Taşdemir ve Sempozyumun düzenlenmesinde aktif rol üstlenen Lisans Programı öğrencilerimiz ayrı bir teşekkürü fazlasıyla hak ettiler.

Sempozyum beklentilerimizin üstünde büyük bir ilgiyle karşılanıp yapılan sunumların niteliğinin yüksekliği izleyiciler tarafından öne çıkarılınca sunulan bildirilerin bir kısmını yayına dönüştürme eğilimi belirdi. Bu eğilim Sempozyum katılımcıları ve konuya ilgi duyan diğer meslektaşlarımızla paylaşıldı. Ancak bildirilerin çoğu henüz metne dönüştürülmemiş ve ham haldeydiler. Yazıların makale formatına dönüştürülmesi ve olgunlaştırılması için ilgi duyan katılımcılara belirli bir zaman tanınması kararlaştırıldı. Sempozyum dışından da konuya ilgi duyan bazı meslektaşlarımıza yayın niyeti aktarıldı.

Bir yandan da, çalışmaların nerede yayına dönüştürülebileceği konusu araştırıldı. Sempozyum Hacettepe Üniversitesi, İktisadi ve İdari Bilimler Fakültesi'nde düzenlenmiş olduğu için akla gelen ilk seçeneklerden biri Fakülte Dergisi oldu. Aynı süreçte, Hacettepe Üniversitesi İIBF Dergisi yayın sıklığını arttırmış, bazı sayılarını Özel Sayı olarak tasarlamayı hedefine koymuştu. Bu çerçevede 2015 yılının ikinci yarısı veya 2016 yılının başında çıkarılacak bir sayının özel sayı olarak belirlenmesine ve " 70 . Yllında Bretton Woods Anlaşması"na ayrılmasına karar verildi. $\mathrm{Bu}$ kararın alınmasındaki teşvik edici ve yapıcı tutumlarından dolayı Derginin mevcut sahibi Hacettepe Üniversitesi İ̈BF Dekanı Prof. Dr. Uğur Ömürgönülşen'e ve Derginin Editörü Prof. Dr. Necmiddin Bağdadioğlu'na teşekkürlerimi sunmak isterim. Bu özel sayının davetli editörü olarak benim sorumluluk almamı istediler. Seve seve kabullendim. Umarım bu zorlu işin altından kalkmayı biraz olsun becerebilmişimdir.

Derginin ilerleyen sayfalarında görebileceğiniz gibi, bu özel sayıda altı çalışma yer almaktadır. İlk iki yazı Türkiye'deki iktisat biliminin duayen ve üretken hocalarından Prof. Dr. Bilsay Kuruç ve Prof. Dr. Korkut Boratav'a aittir. Kendilerinden davetli yazar olarak bu özel sayımızda yer almalarını rica ettik. Bizleri kırmadılar. Sempozyum sırasında tutulan bant kayıtlarından da yararlanarak ancak o kayitların da ötesine geçerek ilgi çekeceğini umduğumuz yazılarını dergimize gönderdiler. Bilsay Hoca tarihsel görsellerle süslediği "Bretton Woods Antlaşmasının 70. Ylli" başlıklı yazısında ana tartışma konusunun tarihsel ve kuramsal arka planını okuyuculara sunuyor. Korkut Hoca ise, "IMF: Dün ve Bugün" başlıklı çalışmasında Bretton Woods ikizlerinden Türkiye'de yaşayanların daha yakından bildiği uluslararası kuruluşlarından biri olan İMF'nin geçmişini ve bugününü Türkiye deneyimini de hesaba katarak eleştirel bir bakış açısıyla ele alıyor. 
$\mathrm{Bu}$ iki değerli yazının ardından gelen dört yazı için geleneksel kör hakemlik süreci işletildi. Yazıların tamamı Dergi Yönetim Kurulu tarafından belirlenen hakemler tarafından titizlikle değerlendirildi. $\mathrm{Bu}$ bağlamda, değerli zamanlarını isabetli eleştirileriyle gönderilen makalelerin iyileştirilmesine ayıran hakemlere teşekkürlerimizi sunmak isteriz.

Üçüncü çalışma değerli Hocamız Prof. Dr. Sinan Sönmez'e aittir. Sinan Hoca "Bretton Woods, Fordizm ve Hegemonya" başlığını taşıyan çalı̧̧masında Bretton Woods sistemi ile Fordist birikim rejiminin dünya ölçeğinde yaygınlaşması arasındaki ilişkiden hareketle bir yandan bu yaygınlaşmanın kapitalizmin merkez ve çeperinde yarattı̆̆ 1 farklı etkilere değinmekte, diğer yandan da sistemin 1970'lerin başında çözülmesiyle birlikte birikim rejiminde post-Fordist eğilimlerin canlanmasına dikkat çekmektedir.

Doç. Dr. Muammer Kaymak'ın kaleme aldığı “Hegemonya Tartışmaları Işı̆̆ı̆nda İngiliz ve Amerikan Hegemonyaları: Yönlendirici Hegemonyadan Kural Koyиcu Hegemonyaya" başlıklı izleyen çalı̧̧ma ise, Sinan Sönmez'in açtı̆̆ tartışmayı görece uzun dönemli tarihsel bir perspektiften hareketle farklı bir boyuta taşımaktadır. Yazıda hegemonya tartışmaları temel alınarak, kapitalizmin son iki yüzyıllık geçmişinde sistemin uluslararası düzeyde işleyişini şekillendiren temel ilkeleri ve normları oluşturan İngiltere ve ABD'nin üstünlüğü karşılaştırmalı olarak ele alınmakta ve bu bağlamda Bretton Woods kuruluşlarının işlevi tartışılmaktadır.

"Bretton Woods Kuruluşları, New York Uzlaşısı ve Yoksullukla Mücadele Politikaları" başlıklı beşinci makalede Prof. Dr. Hatice Karaçay Bretton Woods kuruluşlarının yoksullukla mücadele politikalarını kapsayıcı kalkınma yaklaşımını temel alarak incelemekte ve bu politikaların yeni liberal yönelimlerin can simidi olarak ele alınıp alınamayacağını tartışmaktadır. Ek olarak, kapsayıcı kalkınma yaklaşımı çerçevesinde Bretton Woods ikizleri ile Birleşmiş Milletler kuruluşları arasındaki yakınsama tartışmaları da çalışma içinde değerlendirilmektedir.

Yrd. Doç. Dr. Hasan Cömert'in "İmkansız Üçleme'den Imkansız İkilem'e: Bretton Woods Dönemi ve Sonrası Para Politikası" başlı̆̆ını taşıyan çalışması Derginin bu özel sayısının son makalesini oluşturmaktadır. Yazar, Bretton Woods sisteminin işlediği ve sistemin çözüldüğü dönemde uygulanan para politikalarının farklı özelliklerini karşılaştırmalı olarak değerlendirmekte, bunu yaparken de imkansız üçleme kavramını araç olarak kullanmayı önermektedir. 
Gerek düzenlenen Sempozyumda yapılan ilginç sunumlardan gerekse bu Dergi kapsamında gündeme getirilen farklı tartışma konularından ortaya çıkan temel sonuçlardan bir tanesi, bir sistem olarak Bretton Woods'un bundan neredeyse yarım yüzyıl önce çözülmeye başlamasına rağmen, disiplinlerarası pek çok kuramsal ve uygulamaya yönelik tartışma konusuna zemin hazırlayan unsurları içinde barındırmaya devam ettiğidir. Bu özel sayı bu çok boyutlu tartı̧̧ma alanına kısmen ışı tutabildiyse amacına ulaşmış olarak görülebilir.

Katkıda bulunanlara teşekkürlerimizle... 